\title{
A quest for meta-learning gains in a physics serious game
}

\begin{abstract}
This chapter describes how a short, repeated and structured opportunity to reflect (a "reflection amplifier") has been integrated in the storyline of a serious game in order to stimulate the development of a meta-cognitive skill: the ability to selfassess the degree of confidence in own answers. An empirical validation of the approach, conducted with 28 secondary school pupils, delivers an uncommon pattern: while the cognitive benefits - the acquisition of academic knowledge in optics - are negligible and mixed up, the meta-cognitive gains present a raising tendency. The experiment also demonstrates that reflection does not necessarily hamper the game flow, if certain conditions, discussed in the chapter, are met.
\end{abstract}

Today's educational literature is prone to grant virtues to games for supporting learning (Mitchell \& Savill-Smith, 2004). However, questions remain about their potential to train transferable reflective skills (Bopp, 2006; Mac Farlane, Sparrowhawk, \& Heald, 2002), which are considered as key leverage points in a lifelong learning society (Claxton, 2006; European Commission, 2006; Rychen \& Salganik, 2003).

\section{Gaming and thinking}

At first sight the awareness and training of these second-order mental processes seem to entail stopand-think episodes. If taking a step backwards is the hallmark of reflection, it can sound discordant with, or even antagonistic to, the immersive characteristics of games, at least adventure games. Westera, Nadolski, Hummel, and Wopereis (2008, p. 2) rightly summarise this perceived tension: "Especially in higher education, the mental mode of learning which reflects profundity, reflection, concentration and perseverance seems to conflict with the mental mode of gaming which is commonly associated with amusement, fun and relaxation”.

It is therefore not surprising that the few examples of deliberate training of reflection reported in the serious game literature are connected with logics/strategy games, to which introspective pauses are inherent. For instance, Anderson (2002) reports about accounts of $6^{\text {th }}$-grade students playing a game named "Stock Market", designed to help children become familiar with how financial transactions function. One female player says: "This game makes me think how to think". What this statement reveals is that this young learner is beginning to understand the real key to learning; she engages in meta-cognition using a game. Saldaña (2004) has enriched a "Master Mind" game to assess and exert thinking skills with three levels of assistance: support of the meta-cognitive processes internal to each step of task (planning, control, and revision), scaffolding of the main steps composing the whole task, and modelling of the task solution process.

In contrast to the aforementioned examples, this chapter depicts an attempt to harness opportunities to reflect to an educational adventure game. It also provides a first empirical evaluation of the effects of this instructional feature on both the understanding of the to-be-learnt concepts - here properties of the light - and the enhancement of a specific reflective skill: to ascertain the confidence in the quality of one's answers, as explained in the next section. 


\section{Confidence degrees}

In an assessment based only on identifying correct and incorrect answers there is little information available for both teacher and learner, other than right or wrong (Kulhavy \& Stock, 1989; Leclercq, 1982). Adding confidence degrees to evaluation leads to refined considerations about learning and teaching. For instance what conclusion should teachers raise when $95 \%$ of their learners succeed answering a question? What other conclusion if those students only produce a mean confidence of $10 \%$ for their correct answer? Teachers might reconsider their teaching as not completed despite the $95 \%$ of success at the test. Corrective behaviours can also benefit from the externalization of confidence. For instance, a wrong answer given along with a confidence degree of $10 \%$ is better than the same wrong answer with $90 \%$ confidence attached. The students in the latter case convey two erroneous pieces of information: one related to their knowledge and one related to themselves (their belief in their answer's rightness). This situation may be considered as dangerous since students will trust what they think they know.

These examples suggest that learning does not move someone from total ignorance to perfect knowledge. Often people already have some knowledge or representation about what is taught, even if these representation or knowledge is misleading. So evaluation should not be limited to either knowledge (viz. correct answer) and ignorance (viz. incorrect answer). As De Finetti (1965, p. 109) puts it: "Partial information exists. To detect it is necessary and feasible. (...) It is only subjective probability that can give an objective meaning to every response and scoring method".

Fig. 7.1 follows De Finetti's intuition by associating a factual measure of knowledge (obtained through multiple choice questions, Y axis) with a subjective assessment (chosen out of a 6-item scale expressing the percentage of confidence in the answer, $\mathrm{X}$ axis). The output is a "spectral distribution of knowledge" (Hunt, 1993; Jans \& Leclercq, 1999). On the left side, the wrong answers are distributed by the confidence degree (from $-100 \%$ up to $0 \%$ ) given by the learner. In the middle ("omis" bar) are the unanswered questions. On the right side are the correct answers, also distributed by confidence but ranking from left to right from $0 \%$ to $100 \%$. Each rectangle defines a type of relation to knowledge: (a) Dangerous knowledge rectangle (wrong answer/high confidence), (b) Unawareness rectangle (wrong answer, low confidence), (c) Mid knowledge rectangle (right answer, low confidence), and (d) Usable knowledge rectangle (right answer, high confidence).

Compared to the usual "correct/not correct" feedback, such a view on students' performance allows a refined diagnosis about the relevant kind of remediation (cognitive and/or meta-cognitive)

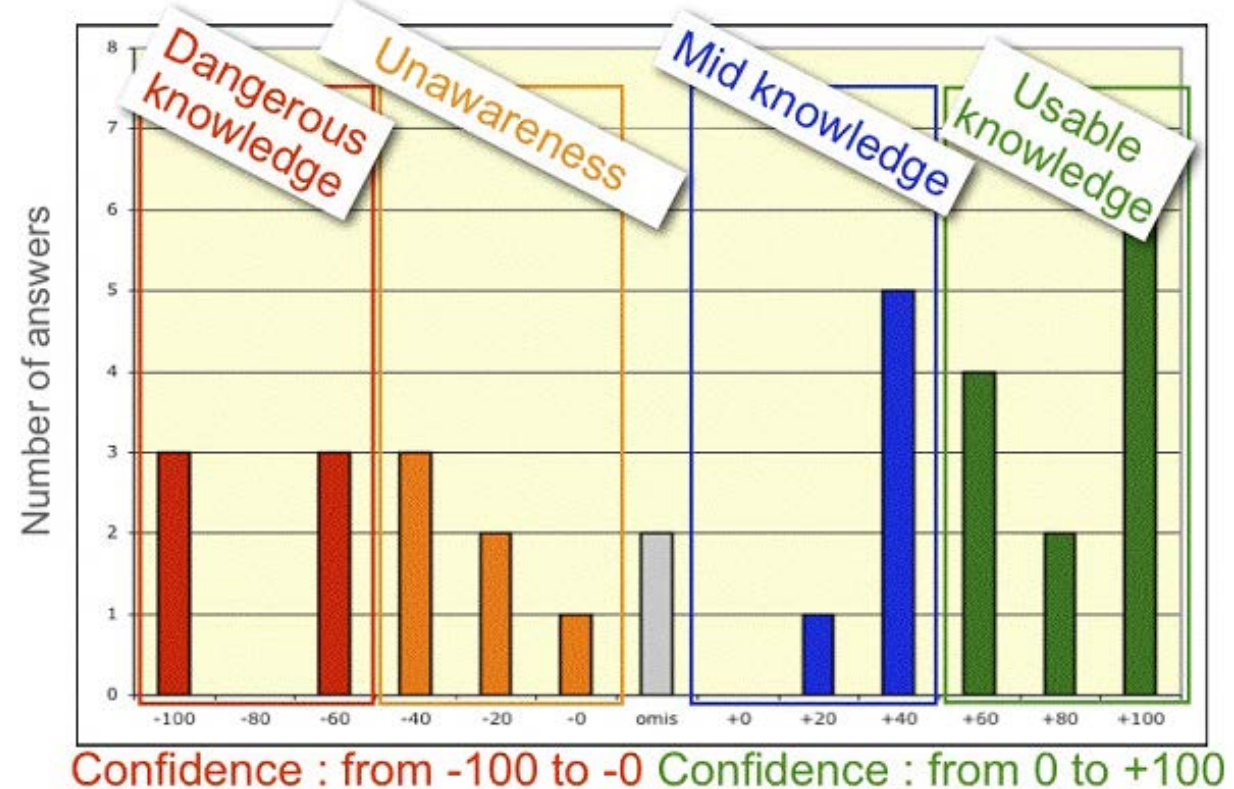

Figure 7.1. A spectral distribution of knowledge spreads student's answers in four categories of knowledge according to a cognitive dimension (right or wrong) and a meta-cognitive dimension (self-assessed confidence degree). 
This study conceptualises the confidence ratings embedded in the Elektra game as "reflection amplifiers” (Verpoorten, Westera, \& Specht, 2011b). The appellation refers to compact, structured and repeated reflection affordances displayed during learning in order to make aspects of it deliberate objects of attention. Reflection amplifiers (RAs) feature clear-cut reflective operations interlaced with the cognitive processes at work for the completion of a first-order learning task. The underpinning assumption tied to RAs is that, by continuously interpreting their actions in terms of personal relationship to knowledge (here, the inner confidence in own answers), learners develop an increased awareness of and an intensified presence to the learning process itself.

\section{Research questions}

In an exploratory study, 28 secondary school pupils trained cognitive (academic knowledge in optics) and meta-cognitive (confidence degrees) skills by playing a version of the game Elektra. The whole experiment was guided by two research questions: (a) how can a RA be reasonably implemented in the concrete of a learning game?, and (b) what will be the effect of such an instructional feature, respectively on the game-play and on (meta-)learning? With regard to the research question b, it must be noted that the influence of a confidence degree rating tool was difficult to ascertain beforehand due to possible ambivalent effects.

On the one hand, RAs represent a reflective pause in the learning process. As such, they can be perceived as game-play "breakers". If explicit calls to reflection harm storytelling and immersion, there is a risk to decrease learners' motivation, one of the main levers of learning in games, according to their proponents (Egenfeldt-Nielsen, 2011). With less motivation, players may not exert sufficient effort to engage in learning.

On the other hand, RAs are designed in such a way that they minimise the disruption (they represent rather short episodes of reflection) and are integrated in the storytelling (gaining confidence in own answers is part of the hero's missions. See section "Storytelling aspect"). So, RAs can also turn to be useful to the support of the first-order learning/gaming task (for a similar dilemma with another RA self-explanation - see Mayer \& Johnson, 2010).

\section{Method}

\section{Context}

The experiment took place in the context of the European project Elektra. The goal of the project was to develop the demonstrator of a state-of-the-art 3D adventure game teaching physics according to national curricula. The demonstrator targeted 13+ students (www.elektra-project.org).

\section{Sample}

Data was collected from 28 pupils from a college in Thiais, France (mean age $=14$ years old, male/female $=58 / 42 \%)$.

\section{Type of game}

Elektra was designed as a typical first person adventure/thriller game wherein a character named George had to rescue Lisa and her Uncle Leo, a researcher, who were kidnapped by a villain secret society. Whilst the plot was set the day of the next solar eclipse in Europe - in the year 2026 - the rescue operation undertaken by George partly immersed him in the world of the Renaissance and its scientific achievements. (The trailer of the game is available at: http://player.vimeo.com/video/24224447?title=0\&amp;byline=0\&amp;portrait=0\&amp;color=ff2e90). To save his friends (and incidentally the earth), George had to confront with concepts from an $8^{\text {th }}$ grade physics course and to get acquainted with them. Yet, using this knowledge was a condition to move forward in his quest. Learning occurred through various modes of engagement with notions, ranging from hearing or reading to freely experimenting. After discovering a magic hour-glass, George 
found himself in company of the ghost of Galileo Galilei (Fig. 7.2, label a) who observed and tutored him when confronted to the physics experimentations. Elektra developed only a demonstrator of the game, namely the opening sequence and the first secret room that George encountered on the track of the evil kidnappers.

\section{Apparatus}

Story-wise, the game element the current empirical study was concerned with was located in the basement of Uncle Leo's villa. It presented as a device that allowed balls (as an implicit reference to corpuscular premises of naïve physics) of different materials rolling down a slope (Fig. 7.2).

During the game, a ball appeared at the top of the slope (Fig. 7.2, label b). The player had to get it into the hole (Fig. 7.2, label c). In case of success, the next ball, made of a different material, was offered for play. Learners could make as many attempts as they wished with each ball. Each trial gave them an opportunity to alter the trajectory of the ball (Fig. 7.2, label d) by adjusting the magnet (Fig. 7.2, label e) and/or the fan (Fig. 7.2, label f) with the sliders (Fig. 7.2, label g, shuffled forces between 1 and 100). By contrast - and this was the chief knowledge to acquire at this experimentation table - a laser ray (Fig. 7.2, label h) could not be influenced by such external forces.

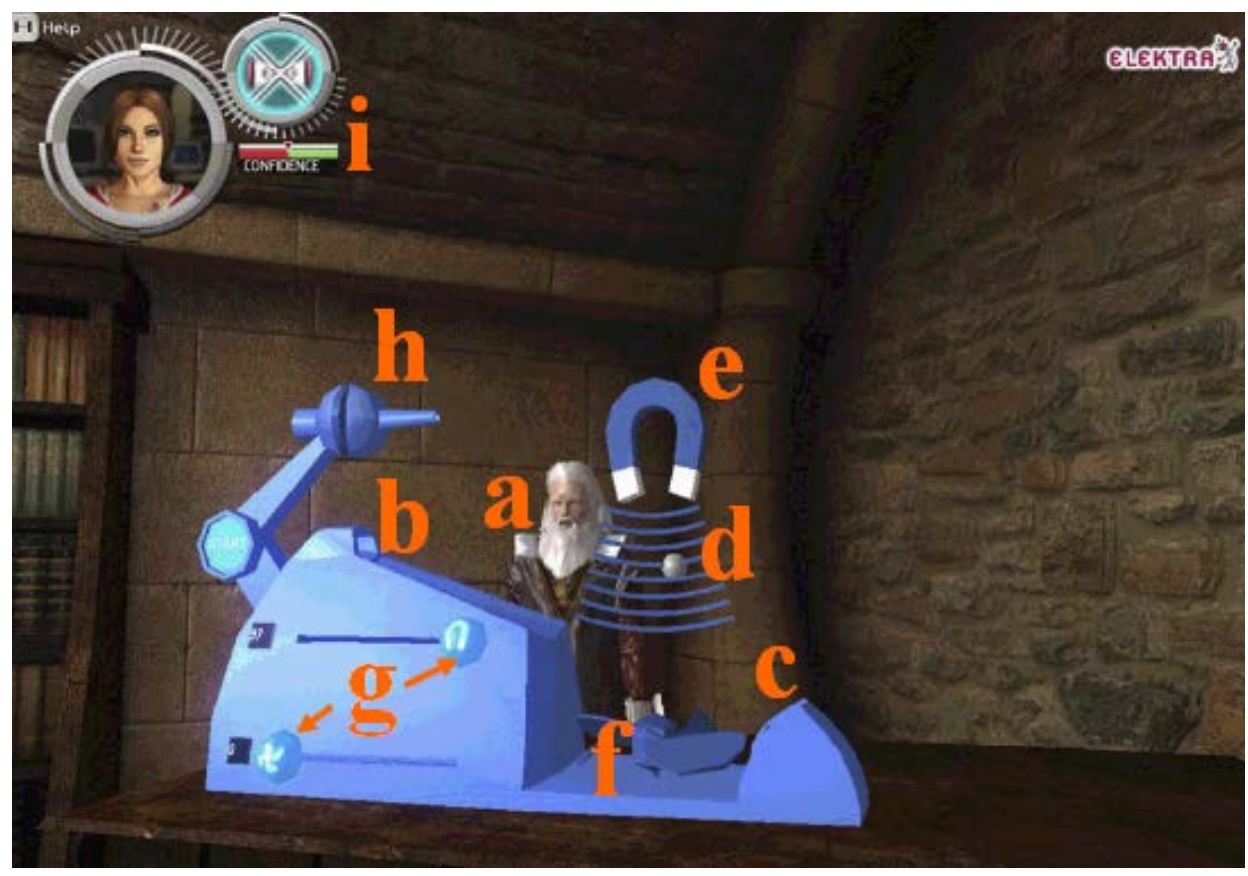

Figure 7.2. The "Slope device" was dedicated to the exploration of light properties.

With regard to the meta-cognitive instructional goal, for the ball to be released (and the effects of the magnet/fan arrangements to be observed), players had to state their degree of confidence that it would land into the hole with this configuration of forces.

A literature review and an empirical pre-study (23 participants) was carried out in order to identify the most relevant metric to express confidence on the slider (for an extensive discussion of this topic, see Castaigne, 2007). Based on the different arguments, it was decided that the Confidence slider would be graduated with the values $0,20,40,60,80$, and $100 \%$ confidence.

As soon as the confidence degree was provided on the dedicated slider (not represented on Fig. 7.2), the ball started rolling the slope, then felt through the air under the influence of gravity, and if applicable, under the influence of the magnet and/or fan, as fixed by players, who then saw whether or not they managed to hit the target.

They received right after two pieces of feedback: one related to the success/failure of the task (e.g., "Well done. You noticed that the magnet had no influence on the aluminium ball and you controlled well the power of the fan") and one related to the confidence evaluation (e.g., "You did well with this ball but you indicated a confidence degree of $20 \%$. You should trust yourself more”). In the demonstrator, both feedbacks were given as textual monitoring pop-ups. 
Throughout the whole game, the status of learners' confidence in their actions was mirrored to them via a "smart indicator" (Glahn, Specht, \& Koper, 2007), called "Certimeter" (for "Certitude meter") in the narrative (Fig. 7.2, label i). The Certimeter actually displayed the mean confidence degree of the successful trials, as computed real-time by the system. Colours went from red to light red between $0 \%$ and $50 \%$ mean confidence and from light green to green from $50 \%$ to $100 \%$ mean confidence (see section "Storytelling aspects" for the connection between the Certimeter and the plot).

The joint setting of the Confidence slider and the Certimeter supported a visual and systematic coordination between the game-play and the evolution of the meta-cognitive skill. The Certimeter was updated after each provision of a confidence degree. Players trained themselves with five balls made successively of iron, plastic, wood, aluminium, granite.

\section{Learning aspects}

The learning goals of Elektra drew on the usual distinction between specific skills (confined to a domain, here: optics) and generic skills (domain-independent, transferable, here: confidence ranking). The selection of the pedagogical endeavours of the game came on top of huge preparatory work: European curricula comparisons, breakdown of identified skills in various granularity levels, distribution of the retained skills in the entire game-play. (This work, with its difficulties and limitations, is documented in Petit, Castaigne, and Verpoorten, 2007).

\section{Cognitive goal}

The main learning goal associated with the Slope device shown in Fig. 7.2 was to support the understanding that light propagated in straight lines, as opposed to the curved trajectories of other objects when they were under the influence of forces (wind, magnet, gravity).

\section{Meta-cognitive goal}

The setting altogether pursued a meta-cognitive objective: to develop the awareness of players regarding the confidence they had in their previsions about the trajectory of the balls and of the light.

\section{Storytelling aspects}

Cognitive and meta-cognitive learning goals harnessed to the Slope device underwent a careful integration in the storyline (Moser, 2000): the acquired knowledge about light properties was needed to move further in the adventure. In this case, learners had to use what they had learnt with the Slope device to - late on - unlock the door to the next room, by exactly hitting a small light sensor with a laser beam.

Meta-cognitive progress was also rewarded from a game-play perspective: George had to gain the trust of Galileo and this trust evolved on the basis of the good use of the confidence degrees. Indeed, George had to succeed at discovering the different influences of the fan and the magnet (and their lack of effect on the light ray) but he had concurrently to reach a green level score on the Certimeter (Fig. 7.2, label i), meaning that Galileo could trust him when he said that he was sure of his knowledge or when he said that he had doubts (a transversal skill and a pre-condition to any scientific work).

\section{Procedure}

Participants filled in the pre-questionnaire (see the next section "Measure instruments") to assess the current state of their knowledge for the part of the curriculum covered by the game. Afterwards, they received a briefing about the game, confidence degrees and the Slope device. They played it $30 \mathrm{~min}$ at the most and then took the post-questionnaire which evaluated their state of knowledge after the gaming session.

\section{Measure instruments}

A pre/post-test comparison and a test inserted in the game measured cognitive and meta-cognitive performance. Both tests could be taken only once. 


\section{Pre/post-test}

Before and after the gaming session, pupils answered with paper and pencil to one question about the influence of wind on a ray of light and another one about the influence of magnet on a ray of light.

\section{Intermediate test (within the game)}

This test came after the players succeeded in throwing the third ball (wood) in the hole. It was designed as a formative test designed to bring a contrast to the reflection triggered by the manipulations around the previous balls. The test presented three questions (Fig. 7.3) probing successively the presumed effect of the fan, the magnet and the combination of both on the laser ray. Students gave their answer by clicking on the visual representing in their view the correct trajectory. For each answer, they were asked as usual to indicate their confidence degree. They did not receive any kind of feedback on their answers. After the test, players went on with the final two balls in an identical manner to the previous ones.
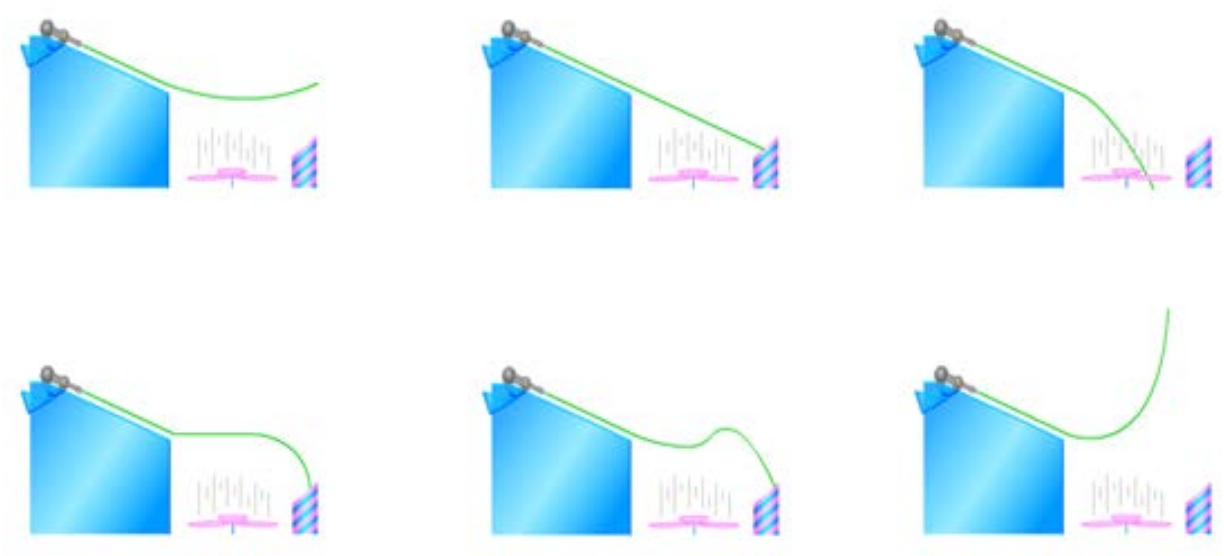

Figure 7.3. To perform the intermediate test embedded in the game, players had to click on the visual giving the correct representation of how a laser ray would propagate in a given situation (here with the fan activated).

\section{Results}

\section{Whole game}

Students performed an average of four trials with each ball before achieving success. The overall mean confidence (all attempts, all pupils, $N=28$ ) was $54 \%$.

\section{Pre/post-test}

Between the pre-test and the post-test, the group of pupils did not enhance its performance when answering if magnetism influenced trajectory of light $(t(54)=1.65, p=.1, d=0.44)$ and if wind influenced the trajectory of light $(t(54)=1.44, p=.15, d=0.39)$.

\section{Intermediate test}

The relationship between right answers and mean confidence degrees are summarised in Table 7.1 for the intermediate test (three questions with visuals as answers, see Fig. 7.3). Results showed a steady progression in the confidence that students had in the rightness of their answers. While the average confidence associated to the trials with the balls (54\%, see the section "Whole game") and to the first multiple-choice question (MCQ\#1: 55\%, Table 7.1) were still in the Mid-knowledge rectangle (see Fig. 7.1 in section "Confidence degrees"), it toppled over the Usable knowledge rectangle for the two last questions. 


\begin{tabular}{lccc}
\hline \hline & MCQ\#1 & MCQ\#2 & MCQ\#3 \\
\cline { 2 - 4 } Correct answers $(N)$ & 19 & 14 & 22 \\
Mean degree of confidence & $55 \%$ & $65 \%$ & $84 \%$ \\
\hline
\end{tabular}

A one-way ANOVA exhumed that the differences of mean confidence degree reported for the correct answers in the three MCQs (Table 7.1) were significant, $F(2,52)=3.19, p=.49, \eta_{p^{2}}=.12$. Additional Fisher contrast tests on pair-wise comparisons disclosed that the mean difference was significant between MCQ\#1 and MCQ\#3 ( $p=.01)$.

\section{Discussion and further work}

The sample of this study remains limited, as well as the extent of the assessment procedure, conducted after a rather short training period. It must also be noted that, for scientific purpose, this experiment did use a trimmed version of the Elektra demonstrator. Lastly, due to limited tracking facilities, the study had to limit itself to between-subjects measures. These limitations considered, four main findings emerge. Each of them contributes to a specific research field.

\section{Contribution to research on meta-cognitive development}

One can ask if meta-cognition, and especially its self-assessment component, is usable as such for teenagers of this age. In brief, major works in the field consider that the components of meta-cognitive monitoring and control do not significantly differ between adults and 10 years old children. Below the age of 10, meta-cognitive processes evolve with age. For instance, Flavell, Friedrichs, and Hoyt (1970) provided evidence of significant correlation between predicted and actual memory span in children from the $4^{\text {th }}$-grade but no significant correlation was found below that age, including at nursery and kindergarten. Schneider (2008) observed unrealistic performances prediction in young children and outlined three reasons: 1) insufficient meta-cognitive knowledge: young children do not monitor their memory activities or lack in understanding about the interplay of relevant factors, 2) predominance of wishful thinking over analytical expectations: children's predictions reflect their desires, and 3) belief in the power of effort: the mere fact of spending time on a task induces the prediction of success. Duell's findings (1986) brought further evidence that as children get older they demonstrate more awareness of their thinking processes. This study comforts these previous works by evidencing that teenagers understand the idea of confidence in own answers and can practise systematic exercise based on this meta-cognitive notion.

\section{Contribution to research on confidence degrees}

Previous works in the field of confidence ranking have generally noted that learners tend to overestimate the quality of their answers, especially in areas where their skills and knowledge bases are weak (Ehrlinger, Johnson, Banner, Dunning, \& Kruger, 2008; Kruger \& Dunning 1999; O’Hanlon \& Diaz, 2010). In other words, it has been regularly observed that students do not know enough to recognise that they lack sufficient knowledge for accurate self-assessment. The pattern observed in this experiment does not fit well in this overestimation tendency. Self-assessment episodes in the Intermediate test do not show high confidence degrees but a progression towards higher levels when good answers are given (see Table 7.1). It advocates for an excipient understanding of the connection between rightness and certainty. After all, it would have been possible that pupils only focus on reaching the target with the ball, neglecting the reflection on their actions and disregarding or using superficially the Confidence slider. On the contrary, the answers provided reflect serious metacognitive thinking. This fair level of engagement with reflection can be imputed to convergent factors:

- during the general introduction to the experiment, students have been briefly explained why gauging their confidence matters for learning. This may have been an important contributor to the quality of confidence rankings. Yet, it is generally acknowledged that the rationale given for the usefulness of meta-cognitive interventions is a success factor thereof (Bannert, 2006); 
- from an instructional game design viewpoint, it is plausible that the encapsulation of confidence degree, both in local challenges and at the global storytelling level, contributed to their being taken seriously;

- the brevity of the reflective enactments (following a salient feature of RAs) is another aspect that probably played a positive role, challenging the idea that a reflection is necessarily a longlasting operation.

Further investigation is needed to disentangle the respective influence of these factors.

\section{Contribution to the integration of reflection in games}

In her effort to understand the interplay and relationships between different kinds of learning environments and methods, Laurillard (1993) emphasises that standard classroom, lecture and exercise techniques can lack in context, interactivity, and the ability to experiment freely. Conversely, games offer these features but have their own shortcoming, in that they might be weak at providing students with opportunities to initiate reflection and to describe their conceptual knowledge ${ }^{1}$. Harteveld, Guimarães, Mayer, and Bidarra (2007, p. 132) note in a convergent way:

Games offer almost no opportunity for reflection as players are completely immersed into the game. Reflection is important to go from specific spontaneous concepts towards abstract scientific concepts. Reflection can be stimulated by an instructor, but it could be a valuable addition if it was somehow included into the game.

Elektra challenges views on game that consider this medium as inappropriate for reflective pauses. When thinking episodes are carefully crafted, when they are kept short and active and when they make sense for the next steps of the game-play, it seems that they can bring an added value without destroying the "flow of optimal experience" (Csikszentmihalyi, 1990).

How to strike the right balance between action and thought remains however a complex question. On the action side, Kiili (2004, p. 16) states that: "Ambitions to design engaging educational games have probably often failed because educational aspects have displaced game-play”. But conversely, on the education side, it is legitimate to raise the question of the extent to which the game-play should take the precedence over the examination of the task at hand and the conscious internalization of conditions of success, possibly at the expense of learning and meta-learning. Effective trade-offs is a research topic that deserves additional inquiry (Kim, Park, \& Baek, 2009).

\section{Contribution to an extended definition of learning performance}

What is students' learning performance in Elektra's gaming sequence? If performance is resumed to its traditional definition - enhancement of the mark at the test - the answer is "nothing". Section "Pre/post-test" highlights that learning gains do not occur.

This can probably be imputed to a poor serious game sequence. The knowledge to acquire is very limited. Furthermore, the basic optics principles to be learnt - that light propagates in straight line and is not influenced neither by the magnet nor by the fan or the gravity - may be trivial and already preexisting in the knowledge of 14 years old students. In addition, the players do not manipulate straight

\footnotetext{
${ }^{1}$ Any learning method has its shortcomings, but well-thought aggregates can combine their strengths. The diversification of learning methods and approaches is not only a matter of students' motivation enhancement but also of epistemology (Moss, 2002; Verpoorten, Poumay, \& Leclercq, 2007). For this reason, learning games should more often be contextualised within a larger learning sequence and not conceived as stand-alone vectors of learning, as recommended by Quinn (2005, p. 14), "I do not believe that these engaging learning experiences of games will (or should be expected to), by themselves, lead to learning. I advocate discussion around the experience, and connecting learner actions to the underlying concept. As yet, computers are not quite capable of supporting such dialogue. Self-directed learners may be capable of facilitating their own reflection, but it's not the way to bet (though I believe strongly that meta-learning, or learning to learn, is a key leverage point for the future). So although such gaming environments are not sufficient, they are necessary; we need engaging experiences to motivate learners to attend to the content, give them rich practice opportunities, and provide fodder for discussion and refinement of their understanding”. De Freitas (2006, p. 11) puts a similar emphasis on embedding learning games in larger instructional learning sequences. By curiosity, the young players of Elektra were asked whether they would prefer gaming before or after a lecture on light properties. Results gave a striking even proportion of "before" and "after" answers (Verpoorten, Glahn, Chatti, Westera, \& Specht, 2011, p. 281).
} 
the laser. Instead, visualisations of the trajectory of light are provided during the exercises with the balls in the hope that some contrast is created (see Fig. 7.3). Given these flaws, it seems that the game is doomed from a cognitive performance viewpoint.

However, a similar failure is not found in the field of meta-cognition. With regard to the training of one specific kind of intellectual habit - the ability to assess one's certitude/doubt about knowledge the study provides indications that the game produced positive effect, as attested in the progression of the mean confidence degree observable in Table 7.2. This is the interesting result of the study: albeit no academic knowledge is learnt, a learning gain occurs anyway in the realm of meta-cognition, due to the presence and the activation of a RA.

This somewhat paradoxical finding ("nothing is learnt on a certain level but something is learnt on another one") would even be better highlighted if the same experiment could be replicated, not with "confidence degrees" (degree of confidence related to right answers), but with "prudence degrees" (degrees of confidence related to wrong answers).

"Confidence" deals only with good answers and is restricted to the evolutions in the rectangles "Mid knowledge" and "Usable knowledge" (see Fig. 7.1). In case of confidence progression, students win in both landscapes: cognitive and meta-cognitive.

A symmetric empirical study would be worth conducting on the failed answers and the confidence degrees attached to them (usually referred in the literature as "prudence"). Evidence of gains in prudence (for instance students leaving the "Dangerous knowledge" area to enter in the "Unawareness" realm) would reveal progress being made in the face of the delivery of wrong answers! The answers would still be wrong but students would have learnt to be more prudent regarding their conviction that they are good.

This would revamp, at the age of learning games, the invitation of Piaget (1978) to distinguish between success and understanding, between progress visible at the test (in the case of prudence, progress measured as a test score amounts to nihil) and intangible benefits (getting the grip on an essential intellectual skill: being conscious of own ignorance) which cannot be traced by the traditional modes of assessment and are not reflected into regular learning achievement measures. Such a work on prudence degrees would be a natural extension of this chapter in future research.

\section{Conclusion}

It can eventually be concluded that this experiment - which, for the first time to the best of authors' knowledge, makes use of confidence ranking as a reflection amplifier in an adventure game - points at a potential for this type of game to develop not only the ability to perform (cognitive goal), but also to engage learners at meta-levels of learning.

\section{References}

Anderson, N. J. (2002). The Role of Metacognition in Second Language Teaching and Learning. ERIC Digest: ERIC Clearinghouse on Languages and Linguistics, 4646 40th Street N.W., Washington, DC 20016-1859. Tel: 202-362-0700. http://www.cal.org/ericcll/DIGEST.

Bannert, M. (2006). Effects of reflection prompts when learning with hypermedia. Journal of Educational Computing Research, 4, 359-375.

Bereiter, C., \& Scardamalia, M. (1989). Intentional learning as a goal of instruction. In L. Resnick (Ed.), Knowing, learning, and instruction: Essays in honor of Robert Glaser (pp. 361-392). Hillsdale, NJ: Lawrence Erlbaum Associates.

Bopp, M. (2006). Didactic Analysis of Digital Games and Game-Based Learning. In M. Pivec (Ed.), Affective and Emotional Aspects of Human-Computer Interaction. Game-Based and Innovative Learning Approaches (pp. 8-37). Amsterdam: IOS Press.

Castaigne, J.-L. (2007). Game based learning and metacognition: working with quantitative metacognitive feed-back based on subjective probability without loosing the game play. Paper 
presented at the 12th biennial Conference EARLI: Developing Potentials for Learning. http://earli2007.hu/nq/home/scientific_program/programme/proposal_view/\&abstractid=1757.

Claxton, G. (2006). Expanding the Capacity to Learn: A new end for education?. Keynote speech given at British Educational Research Association Annual Conference, University of Warwick, 6-9 September 2005, .

Csikszentmihalyi, M. (1990). Flow: The Psychology of Optimal Experience. New York: Harper and Row.

De Finetti, B. (1965). Methods for discriminating levels of partial knowledge concerning a test item. British Journal of Mathematical and Statistical Psychology, 18, 87-123.

de Freitas, S. (2006). Learning in Immersive Worlds: A Review of Game-based Learning. Bristol, England: JISC. http://www.jisc.ac.uk/media/documents/programmes elearninginnovation/gamingreport_v3.pdf

Duell, O. K. (1986). Metacognitive skills. In G. Phye \& T. Andre (Eds.), Cognitive Classroom Learning: Understanding, thinking and problem solving (pp. 205-239). Orlando, FL: Academic Press.

Egenfeldt-Nielsen, S. (2011). What Makes a Good Learning Game? - Going beyond edutainment. http://elearnmag.acm.org/archive.cfm?aid=1943210

European Commission. (2006). Proposal for a recommendation of the European Parliament and of the Council on key competences for lifelong learning. COM(2005)548 final. Brussels.

Flavell, J. H., Friedrichs, A. G., \& Hoyt, J. D. (1970). Developmental changes in memorization processes. Cognitive Psychology, 1(4), 324-340.

Glahn, C., Specht, M., \& Koper, R. (2007). Smart indicators on learning interactions. In E. Duval, R. Klamma \& M. Wolpers (Eds.), EC-TEL 2007 LNCS 4753 (pp. 56-70). Berlin, Heidelberg: Springer.

Harteveld, C., Guimarães, R., Mayer, I., \& Bidarra, R. (2007). Balancing pedagogy, game and realitycomponents within a unique serious game fortraining levee inspection. Paper presented at the Second International Conference, Edutainment 2007.

Hunt, D. (1993). Human self-assessment : Theory and application to learning and testing. In D. Leclercq \& J. Bruno (Eds.), Item Banking : Interactive Testing and Self-Assessment (Vol. F 112, pp. 177-189). Berlin: Springer Verlag.

Jans, V., \& Leclercq, D. (1999). Mesurer l'effet de l'apprentissage a l'aide de l'analyse spectrale des performances. In C. Depover \& B. Noel (Eds.), Evaluation des compétences et des processus cognitifs (pp. 303-317). Bruxelles: De Boeck.

Kiili, K. (2004). Digital game-based learning: Towards an experiential gaming model. Internet and Higher Education, 8(1), 13-24.

Kim, B., Park, H., \& Baek, Y. (2009). Not just fun, but serious strategies: Using meta-cognitive strategies in game-based learning. Computers \& Education, 52(4), 800-810.

Kruger, J., \& Dunning, D. (1999). Unskilled and unaware of it: how difficulties in recognizing one's own incompetence lead to inflated self-assessments. Journal of Personality and Social Psychology, 77(6), 1121-1134.

Laurillard, D. (1993). Rethinking university teaching: a framework for the effective useof educational technology. London: Routledge.

Leclercq, D. (1982). Confidence Marking: its use in testing. In Postlethwaite \& Choppin (Eds.), Evaluation in Education (Vol. 6, pp. 161-287). Oxford: Pergamon.

Mac Farlane, A., Sparrowhawk, A., \& Heald, Y. (2002). Report on the educational use of games. An exploration by TEEM of the contribution which games can make to the education process. Cambridge: Department for Education and Skills - TEEM project.

Mayer, R. E., \& Johnson, C. I. (2010). Adding Instructional Features that Promote Learning in a Game-Like Environment. Journal of Educational Computing Research, 42(3), 241-265.

Mitchell, A., \& Savill-Smith, C. (2004). The use of computer and video games for learning. A review of literature. UK: Learning and skills development agency.

Moser, R. (2000). A methodology for the design of educational computer adventure games. http://www.library.unsw.edu.au/ thesis/adt-NUN/public/adt-NUN20021003.141152. 
Petit, L., Castaigne, J.-L., \& Verpoorten, D. (2007). Checking the internal pedagogical consistency of a game learning situation: the Leclercq's triple consistency triangle. Paper presented at the Evete Conference 2007, Kaunas, Lithuania.

Piaget, J. (1978). Success and Understanding. Cambridge, Massachusettes. : Harvard University Press.

Quinn, C. (2005). Engaging learning - Designing e-Learning simulation games. San Francisco, CA: Pfeiffer.

Rychen, D. S., \& Salganik, L. H. (2003). Key Competencies for a Successful Life and a WellFunctioning Society: Hogrefe Publishing.

Saldaña, D. (2004). Dynamic Master Mind. School Psychology International, 25(4), 422-438.

Schneider, W. (2008). The Development of Metacognitive Knowledge in Children and Adolescents: Major Trends and Implications for Education. Mind, Brain, and Education, 2(3), 114-121.

Verpoorten, D., Glahn, C., Chatti, A., Westera, W., \& Specht, M. (2011). Self-Reported Learning Effects of a Tagging Activity Carried out in a Personal Learning Environment (PLE) by Secondary-School Pupils. International Journal for Cross-Disciplinary Subjects in Education, 2(1), 276-284.

Verpoorten, D., Poumay, M., \& Leclercq, D. (2007). The eight learning events model: A pedagogic conceptual tool supporting diversification of learning methods. Interactive Learning Environments, 15(2), 151-160.

Verpoorten, D., Westera, W., \& Specht, M. (2011). Reflection Amplifiers in Online Courses: A Classification Framework. Journal of Interactive Learning Research, 22(2), 167-190.

Westera, W., Nadolski, R. J., Hummel, H. G. K., \& Wopereis, I. G. J. H. (2008). Serious games for higher education: a framework for reducing design complexity. Journal of Computer Assisted Learning, 24(5), 420-432. 